\title{
Clinical Relevance and Characteristics of Aspergillus calidoustus and Other Aspergillus Species of Section Usti
}

\author{
Emmanouil Glampedakis ${ }^{1}$, Véronique Erard ${ }^{2}$ and Frederic Lamoth ${ }^{1,3, *}$ \\ 1 Infectious Diseases Service, Lausanne University Hospital and University of Lausanne, \\ 1011 Lausanne, Switzerland; emmanouil.glampedakis@chuv.ch \\ 2 Clinique de Médecine et spécialités, infectiologie, HFR-Fribourg, 1708 Fribourg, Switzerland; \\ Veronique.Erard@h-fr.ch \\ 3 Institute of Microbiology, Lausanne University Hospital and University of Lausanne, \\ 1011 Lausanne, Switzerland \\ * Correspondence: frederic.lamoth@chuv.ch; Tel.: +41-21-314-1010
}

Received: 30 April 2020; Accepted: 4 June 2020; Published: 12 June 2020

\begin{abstract}
The Aspergilli of section Usti (group ustus) are represented by over 20 species, of which Aspergillus calidoustus is the most relevant human pathogen. Invasive aspergillosis (IA) caused by these fungi is rare but could represent an emerging issue among the expanding population of patients with long-term immunosuppression receiving antifungal prophylaxis. Clinicians should be aware of this unusual type of IA, which often exhibits distinct clinical features, such as an insidious and prolonged course and a high occurrence of extra-pulmonary manifestations, such as skin/soft tissue or brain lesions. Moreover, these Aspergillus spp. pose a therapeutic challenge because of their decreased susceptibility to azole drugs. In this review, we outline the microbiological and clinical characteristics of IA due to Aspergillus spp. of section Usti and discuss the therapeutic options.
\end{abstract}

Keywords: Aspergillus ustus; Aspergillus pseudodeflectus; Aspergillus granulosus; Aspergillus insuetus; Aspergillus puniceus; Aspergillus keveii; invasive aspergillosis

\section{Introduction}

Fungi of the genus Aspergillus represent the most important pathogenic molds for humans, causing invasive aspergillosis (IA) in patients with impaired immune defenses. While over 300 Aspergillus spp. have been described, the vast majority of IA cases are attributed to less than five species, consisting mainly of A. fumigatus (60-80\% cases) and A. flavus, A. niger (or related cryptic species) and A. terreus for most of the remaining cases [1-4]. A recent study however suggested that epidemiology of IA may evolve as a consequence of the widespread use of anti-mold azole prophylaxis (i.e., posaconazole or voriconazole) with emergence of Aspergillus of section Usti (group ustus) exhibiting natural resistance to these antifungals [5]. This section includes over 20 species that are ubiquitous molds found in the indoor and outdoor environment [6]. Notably, they were the most frequent Aspergillus spp. found in drinking water distribution systems in Norway, including from hospital tap water [7]. A. ustus and related species were also frequently recovered from water-damaged buildings and from caves affected by human activities [8,9]. While the first case of IA due to Aspergillus of section Usti was described in 1974 [10], these infections have been increasingly reported in the literature since 2000 [11,12].

The aim of this review is to provide a practical summary of what infectious diseases specialists and microbiologists should know about Aspergillus spp. of section Usti for their daily practice. 


\section{Taxonomy and Microbiology}

Based on phylogenetic analyses, there are currently 26 recognized Aspergillus species belonging to section Usti (Table 1) $[6,8,13]$. Most of them, including A. ustus sensu stricto, are unable to grow at $37^{\circ} \mathrm{C}$ and therefore are not considered as human pathogens. Actually, most cases of human infections that were attributed to $A$. ustus in the literature, were secondarily reassigned to a novel distinct species, A. calidoustus, which is able to grow at $37^{\circ} \mathrm{C}$ [14]. Two other closely related species, A. pseudodeflectus and A. granulosus, are also thermotolerant at human body temperature and were also found to be able to cause invasive infections in humans [11,15-17]. A. ustus sensu stricto was also isolated from a patient with aspergillosis localized to the skin and soft tissue [11]. Other non-thermotolerant species of section Usti that were isolated as colonizers or contaminants from clinical specimens include $A$. insuetus, A. puniceus and A. keveii [11].

Table 1. The 26 Aspergillus species of section Usti and their pathogenic role in humans.

\begin{tabular}{ccc}
\hline Isolated in Clinical Specimens & \multicolumn{2}{c}{ Environmental Samples Only } \\
\hline Proven/probable IA ${ }^{1}$ cases & A. amylovorus & A. turkensis \\
A. calidoustus $^{2}$ & A. asper & A. germanicus \\
A. pseudodeflectus & A. baeticus & A. heterothallicus \\
A. granulosus $^{4}$ & A. californicus & A. kassunensis \\
A. ustus $^{5}$ & A. carlsbadensis & A. lucknowensis \\
Colonization only & A. cavernicola & A. monodii \\
A. insuetus & A. collinsii & A. pseudoustus \\
A. keveii & A. deflectus & A. subsessilis \\
A. puniceus & A. egyptiacus & A. thessauricus \\
& A. elongatus &
\end{tabular}

IA: invasive aspergillosis. ${ }^{1}$ Proven probable invasive aspergillosis according to the criteria of the European Organization for Research and Treatment of Cancer (EORTC) and Mycoses Study Group (MSG) [18]. ${ }^{2}$ Major cause of IA in humans [11]. ${ }^{3}$ Three reported cases of probable IA [11,15]. ${ }^{4}$ Two reported cases of proven IA [16,17]. ${ }^{5}$ Single reported case of proven soft tissue IA [11].

Morphological characteristics of Aspergillus spp. of section Usti are usually reliable for identification at the section level. However, species identification would require partial sequencing of the beta-tubulin $(B e n A)$ or calmodulin $(\mathrm{CaM})$ genes, which is not routinely available in most diagnostic microbiology laboratories [11]. Standard sequencing methods targeting the internal transcribed spacer (ITS) or 26-28S rDNA are not reliable enough for identification beyond the section level. Experience with matrix-assisted laser desorption ionization-time of flight mass spectrometry (MALDI-TOF MS) is limited for these rare species and misidentification has been reported [19].

Most species of section Usti will grow at $25-30^{\circ} \mathrm{C}$. Higher temperature $\left(37^{\circ} \mathrm{C}\right)$ allows distinguishing A. calidoustus or other thermotolerant species (e.g., A. pseudodeflectus, A. granulosus) from nonpathogenic species. Colonies are usually apparent between 2 and 5 days of growth. Macroscopic aspects on standard fungal culture media (e.g., Czapek yeast extract agar, Sabouraud or potato dextrose agar) show velvety greyish to brown cinnamon colonies (Figure 1, left) $[6,20]$. The yellowish reverse color with presence of yellow-brown soluble pigment is typical but can be absent for some species and/or according to the culture medium (Figure 1, middle). Under the microscope, conidial heads are usually short and loosely columnar with biseriate phialides (Figure 1, right) $[6,20]$. Conidia typically harbor rough ornamentation. Some specific characteristics (Hülle cells, Ehrlich reaction, growth on creatine, production of extrolites) may help distinguishing the different species, but these methods require the expertise of reference laboratories $[6,20]$. 


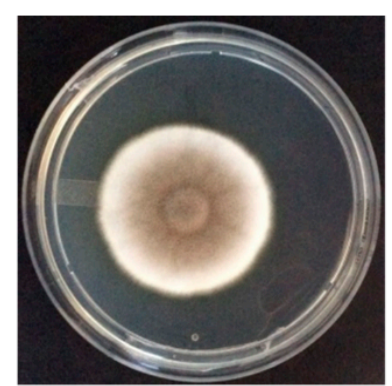

Top

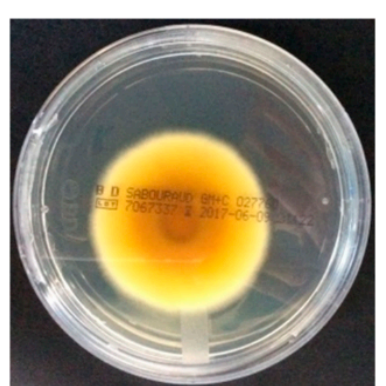

Reverse

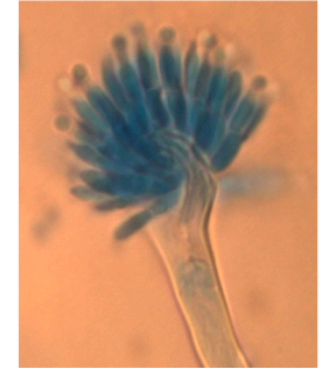

Microscopy (x1000)

Typical features of Aspergillus of section Usti

\begin{tabular}{|l|l|}
\hline Colony morphology & Grey to brown (top), yellowish (reverse). Yellow-brown pigment \\
\hline Conidial head & Short, loosely columnar, biseriate phialides \\
\hline Conidia & Round, brownish with rough ornementation \\
\hline
\end{tabular}

Figure 1. Morphological aspects of Aspergillus calidoustus. Macroscopic aspect of the colony on Sabouraud dextrose agar medium, top (left) and reverse (middle). Microscopic aspect $(1000 \times)$ of a conidial head (staining: lactophenol blue) (right). Note: rough ornamentation of conidia is not visible here and could better visualized by scanning electron microscopy.

Antifungal susceptibility testing shows very similar profiles across species [11,21]. Amphotericin B is the most active drug in vitro with minimal inhibitory concentration encompassing $50 \%\left(\mathrm{MIC}_{50}\right)$ and $90 \%\left(\mathrm{MIC}_{90}\right)$ isolates of 0.5 and $1 \mu \mathrm{g} / \mathrm{mL}$, respectively [11]. Azoles exhibit in vitro activity at concentrations that are usually at the upper limit or beyond the therapeutic range of concentration. Notably, isavuconazole displays somewhat higher activity compared to voriconazole and posaconazole (this latter one being the less active): $\mathrm{MIC}_{50} / \mathrm{MIC}_{90}$ of $2 / 4 \mu \mathrm{g} / \mathrm{mL}, 8 / 8 \mu \mathrm{g} / \mathrm{mL}$ and $16 />16 \mu \mathrm{g} / \mathrm{mL}$, respectively [11]. The fungistatic activity of echinocandins is comparable to that against other Aspergillus spp. with micafungin and anidulafungin exhibiting lower MIC compared to caspofungin [21]. The novel long-lasting echinocandin rezafungin (CD101) and the glucan synthase inhibitor ibrexafungerp (SCY-078) are also active against Aspergillus of section Usti [22,23]. Terbinafine has good in vitro activity (MIC 0.25 to $1 \mu \mathrm{g} / \mathrm{mL}$ ), and its combination with voriconazole was synergistic in vitro and in a Galleria mellonella model of infection [24].

\section{Epidemiology and Clinical Characteristics}

IA caused by Aspergillus section Usti (further referred as A. ustus IA) remains a rare disease. In a cohort of 218 culture positive IA from the Transplant-Associated Infection Surveillance Network (TRANSNET), A. ustus complex species were the fifth cause of IA being responsible for $2.7 \%$ of all cases [25]. In the Prospective Alliance Therapy (PATH) registry, these species accounted for $0.8 \%$ of cases (rank 6th) [4]. In a single center study of 24 microbiologically documented breakthrough invasive mold infections, A. ustus accounted for $12.5 \%$ of all episodes and $43 \%$ of IA [5]. Outbreaks of A. ustus IA have been reported among hematopoietic stem cell transplant (HSCT) or solid-organ transplant (SOT) recipients [26,27]. While these data are mainly derived from North American cohorts, the incidence of A. ustus IA in other regions of the world is not well described.

The largest epidemiological description of proven/probable A. ustus IA included 72 cases, of which 45 were obtained from previous published case reports or small case-series (1974-2018) and 27 were collected via a screening of microbiological databases of 22 European hospital centers (2007-2018) [11]. Most patients were non-neutropenic transplant recipients (47\% HSCT and 33\% SOT recipients) receiving long-term immunosuppressive therapy (anti-calcineurin drugs and/or corticosteroids). About half of them (47\%) had ongoing anti-mold azole prophylaxis (mainly posaconazole) at time of diagnosis. This observation is consistent with the above mentioned epidemiological studies suggesting 
a higher prevalence of $A$. ustus IA among transplant patients and those receiving anti-mold azole prophylaxis $[5,26,27]$.

A. ustus IA were disseminated (i.e., more than one organ affected) in $33 \%$ cases. While the lung was affected in $76 \%$ cases, primary or secondary extra-pulmonary sites of infections were frequently observed. Skin and/or soft-tissue lesions were present in $28 \%$ cases and cerebral aspergillosis in $14 \%$ cases [11]. Serum galactomannan was positive in $85 \%$ patients. Overall mortality was high $(58 \%$ at 6 months, with IA being considered as a major or partial cause of death in $81 \%$ of cases) [11].

In summary, A. ustus IA exhibit some distinct clinical features compared to other IA, as they seem to affect mainly non-neutropenic transplant patients receiving anti-mold active prophylaxis and have a propensity to cause primary or secondary skin lesions or other extra-pulmonary foci of infection. The clinical case presented in Box 1 is illustrative of these characteristics and shows the insidious course of this fungal disease with notably the positive galactomannan in serum preceding the clinical signs of infection by several weeks or months.

Box 1. Illustrative case of Aspergillus calidoustus invasive aspergillosis.

A 64-year old woman underwent allogeneic hematopoietic stem cell transplantation for acute myeloid leukemia.
Three years later, she was treated by two chemotherapy cycles (FLAG and FLAG-IDA) for two consecutive
relapses of the hematologic cancer, followed by maintenance therapy with azacitidine and sorafenib. She was
receiving tacrolimus and corticosteroids for cutaneous and digestive graft versus host disease (GVHD).
Antifungal prophylaxis with posaconazole was administered with appropriate trough concentrations ( $>0.5 \mathrm{mg} / \mathrm{L})$.
During follow-up, an increase in serum galactomannan was observed with a first positive value at 1.8 (optical
density index), while she was asymptomatic. Three months later, she noticed painless skin nodules on her
right leg, upper back and axillary hollow. Serum galactomannan at this time was persistently positive (6.43).
Histopathological examination of the nodules revealed subcutaneous granulomas with mycelial elements.
Cultures of skin biopsy grew a mold identified as an Aspergillus group ustus by sequencing of the 26-28S rDNA
and identified at species level as Aspergillus calidoustus by partial sequencing of the beta-tubulin (BenA) and
calmodulin (CaM) genes. Total body CT and 18 F-FDG PET/CT did not reveal any other lesion.
The patient received multiple antifungal treatment lines (liposomal amphotericin B with caspofungin,
voriconazole with terbinafine, liposomal amphotericin B with caspofungin and terbinafine). Following surgical
excision of all skin nodules, she experienced a recurrence of infection with suspected fungal arthritis of the right
shoulder, which was treated by intra-articular injections of amphotericin B. A reduction of the immunosuppressive
regimen was attempted, but the patient experienced a flare of GVHD and ultimately died. While all clinical foci
of infection had resolved, serum galactomannan was persistently positive at time of death. Autopsy however
did not reveal evidences of remaining invasive mold infection.

\section{Treatment}

As previously mentioned, the species of Aspergillus section Usti exhibit high MICs to the azole drugs, which represent the first-line antifungal therapy of IA [28]. As a result, current guidelines recommend the use of amphotericin B lipid formulations, which are the most active drug in vitro [28]. In practice, antifungal management is difficult with frequent use of multiple antifungal agents, either consecutively or in combination (Box 1) [11]. Interestingly, our analysis of the 72 A. ustus IA cases show that voriconazole was used as first-line therapy (i.e., first antifungal drug administered for at least 10 consecutive days) in a substantial proportion of cases [11]. These patients actually seemed to be less immunocompromised (non-HSCT recipients) and less severely ill with IA that were non-disseminated and classified as probable only, in comparison to those who were treated by amphotericin B. Not surprisingly, the mortality rate was significantly lower in this subgroup compared to amphotericin B-treated patients. Because of these evident biases in retrospective non-matched cohorts, it is not possible to draw conclusions about comparative drug efficacy. Nonetheless, it is noteworthy that voriconazole and amphotericin B were equally effective in a Galleria mellonella model of $A$. calidoustus infection [24]. The novel triazole isavuconazole seems to be somewhat more active than voriconazole in vitro, but clinical experience with this drug for the treatment of $A$. ustus IA is still very limited [29]. 
The potential benefit of drug combination is also debated. Indeed, an echinocandin, in combination with amphotericin B or voriconazole, was part of the first-line antifungal regimen in about one third of cases [11]. Some patients also received a combination of amphotericin B and voriconazole. Overall, mortality was high among patients receiving combination therapies, which may actually reflect the severity of the initial presentation of the disease in these cases. In vitro, these drug combinations were classified as indifferent [24]. Only the combination of voriconazole and terbinafine demonstrated a synergistic interaction in vitro and in the Galleria model [24]. While clinical experience with terbinafine for invasive mold infections is very limited, this drug may have an interest as adjunctive treatment for A. ustus IA because of its high penetration in skin and soft tissue and possibly in the brain [30]. Similarly, the combination of voriconazole and terbinafine has been used for other refractory mold diseases, such as scedosporiosis, although its benefit was not demonstrated [31].

From these observations, we can conclude that the optimal therapeutic approach of $A$. ustus IA would still deserve further investigations. Notably, this is another example that in vitro data do not necessarily correlate with clinical efficacy, as it has been previously shown for other difficult-to-treat mold infections [32]. Non-pharmacological parameters, such as recovery of the immune system or the initial severity of the disease with delay in diagnosis may represent the predominant predictors for outcome.

Our personal approach of A.ustus IA, as described in Table 2, is to consider liposomal amphotericin $\mathrm{B}$ as the first-line treatment, especially for severe cases. However, we consider that voriconazole or isavuconazole (this latter drug being even more active in vitro) alone or combined with terbinafine remain possible therapeutic options, in particular for less severe cases (localized and/or probable IA in patients with mild/moderate immunosuppression and in the absence of previous mold-active azole prophylaxis) or as second-line therapy in case of nephrotoxicity of amphotericin B or for maintenance therapy. Posaconazole should be avoided because of its quasi-lack of in vitro activity and the occurrence of breakthrough A. ustus IA with this drug. The role of echinocandins remains unclear, but this drug class could be used as adjunctive therapy in severe cases.

Table 2. Current antifungal therapeutic options against Aspergillus calidoustus and other Aspergillus spp. of section Usti.

\begin{tabular}{|c|c|c|}
\hline Antifungal Drug Classes & Evidences & Comments \\
\hline Amphotericin B & $\begin{array}{l}\text { Relatively good in vitro activity } \\
\quad(\mathrm{MIC} 0.25-2 \mu \mathrm{g} / \mathrm{mL})[11,21] \\
\text { Effective in a Galleria model [24] }\end{array}$ & $\begin{array}{c}\text { Recommended as first-line on the basis of } \\
\text { optimal in vitro activity } \\
\text { (use lipid-based formulation) }\end{array}$ \\
\hline Mold-active azoles & $\begin{array}{c}\text { Relatively low in vitro activity } \\
\text { (MIC } 2-16 \mu \mathrm{g} / \mathrm{mL} \text { ): isavuconazole }> \\
\text { voriconazole }>\text { posaconazole }[11,21] \\
\text { Voriconazole effective in a Galleria model of } \\
\text { infection [24] } \\
\text { Caveat: breakthrough infections frequently } \\
\text { reported (mainly under posaconazole, but } \\
\text { also voriconazole) }\end{array}$ & $\begin{array}{l}\text { Pre-clinical and clinical data suggest possible } \\
\text { use in selected situations (e.g., less severe } \\
\text { cases or second-line/maintenance treatment, } \\
\text { absence of previous mold-active } \\
\text { azole prophylaxis) } \\
\text { Avoid posaconazole }\end{array}$ \\
\hline Echinocandins & $\begin{array}{l}\text { Fungistatic effect: micafungin/anidulafungin } \\
\qquad>\text { caspofungin [21] }\end{array}$ & $\begin{array}{l}\text { May be used in combination with either } \\
\text { amphotericin B or triazoles despite no } \\
\text { evidence of synergism } \\
\text { Few experience as monotherapy, use only if } \\
\text { no other alternatives (preferably micafungin } \\
\text { or anidulafungin) }\end{array}$ \\
\hline Terbinafine & $\begin{array}{c}\text { Relatively good in vitro activity } \\
\text { (MIC 0.25-1 } \mu \mathrm{g} / \mathrm{mL} \text { ) [21,24] } \\
\text { Effective in a Galleria model of infection [24] } \\
\text { In vitro and in vivo (Galleria) synergism with } \\
\text { voriconazole, posaconazole and } \\
\text { isavuconazole [24] } \\
\text { In vitro antagonism with amphotericin B [24] } \\
\text { Accumulation in skin } \\
\text { (no sustained levels in blood) [30] }\end{array}$ & $\begin{array}{l}\text { May be combined with voriconazole } \\
\text { (or isavuconazole) in selected situations } \\
\text { (see above, possible interest in patients with } \\
\text { skin lesions or alternative to amphotericin B } \\
\text { in case of intolerance) } \\
\text { Use as monotherapy not recommended }\end{array}$ \\
\hline
\end{tabular}

MIC: minimal inhibitory concentration, >: activity superior to. 
Novel broad-spectrum antifungal agents are needed to treat $A$. ustus and other refractory mold infections. Some of them provided promising in vitro results. The Gwt1p inhibitor APX001A (E1210) and olorofim (F901318), an inhibitor of pyrimidine biosynthesis, show good activity against Aspergillus species of section Usti $[33,34]$.

\section{Conclusions}

Aspergillus of section Usti (group ustus), in particular A. calidoustus, are increasingly recognized as causal agents of IA, as a possible consequence of the extent of the population of transplant patients with long-term immunosuppression and the widespread use of antifungal prophylaxis. This mold infection is challenging because of its insidious course, atypical presentation and multidrug resistance. Clinicians should suspect $A$. ustus IA in front of a transplant patient with persistently positive galactomannan despite no clinical or radiological evidence of IA or in the presence of skin lesions or soft tissue nodules. Optimal antifungal therapy still needs to be better defined. While amphotericin B is the most active drug in vitro, other antifungals or drug combinations (e.g., voriconazole or isavuconazole +/terbinafine, adjuvant echinocandin) could be considered in selected situations.

Author Contributions: E.G.; V.E. and F.L., draft and redaction of manuscript. All authors have read and agreed to the published version of the manuscript.

Funding: This research received no external funding.

Acknowledgments: F.L.'s laboratory receives financial support from the Santos-Suarez Foundation.

Conflicts of Interest: F.L. took part in advisory boards for Gilead.

\section{References}

1. Kontoyiannis, D.P.; Marr, K.A.; Park, B.J.; Alexander, B.D.; Anaissie, E.J.; Walsh, T.J.; Ito, J.; Andes, D.R.; Baddley, J.W.; Brown, J.M.; et al. Prospective surveillance for invasive fungal infections in hematopoietic stem cell transplant recipients, 2001-2006: Overview of the Transplant-Associated Infection Surveillance Network (TRANSNET) Database. Clin. Infect. Dis. 2010, 50, 1091-1100. [CrossRef] [PubMed]

2. Pagano, L.; Caira, M.; Candoni, A.; Offidani, M.; Martino, B.; Specchia, G.; Pastore, D.; Stanzani, M.; Cattaneo, C.; Fanci, R.; et al. Invasive aspergillosis in patients with acute myeloid leukemia: A SEIFEM-2008 registry study. Haematologica 2010, 95, 644-650. [CrossRef] [PubMed]

3. Pappas, P.G.; Alexander, B.D.; Andes, D.R.; Hadley, S.; Kauffman, C.A.; Freifeld, A.; Anaissie, E.J.; Brumble, L.M.; Herwaldt, L.; Ito, J.; et al. Invasive fungal infections among organ transplant recipients: Results of the Transplant-Associated Infection Surveillance Network (TRANSNET). Clin. Infect. Dis. 2010, 50, 1101-1111. [CrossRef]

4. Steinbach, W.J.; Marr, K.A.; Anaissie, E.J.; Azie, N.; Quan, S.P.; Meier-Kriesche, H.U.; Apewokin, S.; Horn, D.L. Clinical epidemiology of 960 patients with invasive aspergillosis from the PATH Alliance registry. J. Infect. 2012, 65, 453-464. [CrossRef] [PubMed]

5. Lamoth, F.; Chung, S.J.; Damonti, L.; Alexander, B.D. Changing Epidemiology of Invasive Mold Infections in Patients Receiving Azole Prophylaxis. Clin. Infect. Dis. 2017, 64, 1619-1621. [CrossRef]

6. Samson, R.A.; Varga, J.; Meijer, M.; Frisvad, J.C. New taxa in Aspergillus section Usti. Stud. Mycol. 2011, 69, 81-97. [CrossRef]

7. Hageskal, G.; Kristensen, R.; Fristad, R.F.; Skaar, I. Emerging pathogen Aspergillus calidoustus colonizes water distribution systems. Med. Mycol. 2011, 49, 588-593.

8. Novakova, A.; Hubka, V.; Saiz-Jimenez, C.; Kolarik, M. Aspergillus baeticus sp. nov. and Aspergillus thesauricus sp. nov., two species in section Usti from Spanish caves. Int J. Syst. Evol. Microbiol. 2012, 62, 2778-2785. [CrossRef]

9. Polizzi, V.; Adams, A.; Malysheva, S.V.; De Saeger, S.; Van Peteghem, C.; Moretti, A.; Picco, A.M.; De Kimpe, N. Identification of volatile markers for indoor fungal growth and chemotaxonomic classification of Aspergillus species. Fungal Biol. 2012, 116, 941-953. [CrossRef]

10. Carrizosa, J.; Levison, M.E.; Lawrence, T.; Kaye, D. Cure of Aspergillus ustus endocarditis on a prosthetic valve. Arch. Intern. Med. 1974, 133, 486-490. [CrossRef] 
11. Glampedakis, E.; Cassaing, S.; Fekkar, A.; Dannaoui, E.; Bougnoux, M.E.; Bretagne, S.; Neofytos, D.; Schreiber, P.W.; Hennequin, C.; Morio, F.; et al. Invasive aspergillosis due to Aspergillus section Usti: A multicenter retrospective study. Clin. Infect. Dis. 2020. [CrossRef] [PubMed]

12. Seroy, J.; Antiporta, P.; Grim, S.A.; Proia, L.A.; Singh, K.; Clark, N.M. Aspergillus calidoustus case series and review of the literature. Transpl. Infect. Dis. 2017, 19. [CrossRef] [PubMed]

13. Jurjevic, Z.; Peterson, S.W. Aspergillus asper sp. nov. and Aspergillus collinsii sp. nov., from Aspergillus section Usti. Int. J. Syst. Evol. Microbiol. 2016, 66, 2566-2572. [CrossRef] [PubMed]

14. Varga, J.; Houbraken, J.; Van Der Lee, H.A.; Verweij, P.E.; Samson, R.A. Aspergillus calidoustus sp. nov., causative agent of human infections previously assigned to Aspergillus ustus. Eukaryot. Cell 2008, 7, 630-638. [CrossRef]

15. Ait-Ammar, N.; Levesque, E.; Murat, J.B.; Imbert, S.; Foulet, F.; Dannaoui, E.; Botterel, F. Aspergillus pseudodeflectus: A new human pathogen in liver transplant patients. BMC Infect. Dis. 2018, 18, 648. [CrossRef]

16. Fakih, M.G.; Barden, G.E.; Oakes, C.A.; Berenson, C.S. First reported case of Aspergillus granulosus infection in a cardiac transplant patient. J. Clin. Microbiol. 1995, 33, 471-473. [CrossRef]

17. Sutton, D.A.; Wickes, B.L.; Romanelli, A.M.; Rinaldi, M.G.; Thompson, E.H.; Fothergill, A.W.; Dishop, M.K.; Elidemir, O.; Mallory, G.B.; Moonnamakal, S.P.; et al. Cerebral aspergillosis caused by Aspergillus granulosus. J. Clin. Microbiol. 2009, 47, 3386-3390. [CrossRef]

18. Donnelly, J.P.; Chen, S.C.; Kauffman, C.A.; Steinbach, W.J.; Baddley, J.W.; Verweij, P.E.; Clancy, C.J.; Wingard, J.R.; Lockhart, S.R.; Groll, A.H.; et al. Revision and Update of the Consensus Definitions of Invasive Fungal Disease From the European Organization for Research and Treatment of Cancer and the Mycoses Study Group Education and Research Consortium. Clin. Infect. Dis. 2019, 46. [CrossRef]

19. McMullen, A.R.; Wallace, M.A.; Pincus, D.H.; Wilkey, K.; Burnham, C.A. Evaluation of the Vitek MS Matrix-Assisted Laser Desorption Ionization-Time of Flight Mass Spectrometry System for Identification of Clinically Relevant Filamentous Fungi. J. Clin. Microbiol. 2016, 54, 2068-2073. [CrossRef]

20. Houbraken, J.; Due, M.; Varga, J.; Meijer, M.; Frisvad, J.C.; Samson, R.A. Polyphasic taxonomy of Aspergillus section Usti. Stud. Mycol. 2007, 59, 107-128. [CrossRef]

21. Alastruey-Izquierdo, A.; Cuesta, I.; Houbraken, J.; Cuenca-Estrella, M.; Monzon, A.; Rodriguez-Tudela, J.L. In vitro activity of nine antifungal agents against clinical isolates of Aspergillus calidoustus. Med. Mycol. 2010, 48, 97-102. [CrossRef] [PubMed]

22. Ghannoum, M.; Long, L.; Larkin, E.L.; Isham, N.; Sherif, R.; Borroto-Esoda, K.; Barat, S.; Angulo, D. Evaluation of the Antifungal Activity of the Novel Oral Glucan Synthase Inhibitor SCY-078, Singly and in Combination, for the Treatment of Invasive Aspergillosis. Antimicrob. Agents Chemother. 2018, 62, e00244-18. [CrossRef]

23. Wiederhold, N.P.; Locke, J.B.; Daruwala, P.; Bartizal, K. Rezafungin (CD101) demonstrates potent in vitro activity against Aspergillus, including azole-resistant Aspergillus fumigatus isolates and cryptic species. J. Antimicrob. Chemother. 2018, 73, 3063-3067. [CrossRef] [PubMed]

24. Glampedakis, E.; Coste, A.T.; Aruanno, M.; Bachmann, D.; Delarze, E.; Erard, V.; Lamoth, F. Efficacy of Antifungal Monotherapies and Combinations against Aspergillus calidoustus. Antimicrob. Agents Chemother. 2018, 62, e01137-18. [CrossRef]

25. Balajee, S.A.; Kano, R.; Baddley, J.W.; Moser, S.A.; Marr, K.A.; Alexander, B.D.; Andes, D.; Kontoyiannis, D.P.; Perrone, G.; Peterson, S.; et al. Molecular identification of Aspergillus species collected for the Transplant-Associated Infection Surveillance Network. J. Clin. Microbiol. 2009, 47, 3138-3141. [CrossRef]

26. Egli, A.; Fuller, J.; Humar, A.; Lien, D.; Weinkauf, J.; Nador, R.; Kapasi, A.; Kumar, D. Emergence of Aspergillus calidoustus infection in the era of posttransplantation azole prophylaxis. Transplantation 2012, 94, 403-410. [CrossRef] [PubMed]

27. Panackal, A.A.; Imhof, A.; Hanley, E.W.; Marr, K.A. Aspergillus ustus infections among transplant recipients. Emerg. Infect. Dis. 2006, 12, 403-408. [CrossRef] [PubMed]

28. Ullmann, A.J.; Aguado, J.M.; Arikan-Akdagli, S.; Denning, D.W.; Groll, A.H.; Lagrou, K.; Lass-Florl, C.; Lewis, R.E.; Munoz, P.; Verweij, P.E.; et al. Diagnosis and management of Aspergillus diseases: Executive summary of the 2017 ESCMID-ECMM-ERS guideline. Clin. Microbiol. Infect. 2018, 24 (Suppl. 1), e1-e38. [CrossRef] 
29. Mendoza, M.A.; Anderson, A.; Morris, M.I.; Lekakis, L.; Simkins, J.; Prado, C.E.; Martinez, O.V.; Komanduri, K.V.; Camargo, J.F. Successful Treatment of Invasive Fungal Infection Due to Highly Resistant Aspergillus calidoustus in an Allogeneic Hematopoietic Cell Transplant Recipient. Mycopathologia 2020, 185, 399-403. [CrossRef] [PubMed]

30. Hosseini-Yeganeh, M.; McLachlan, A.J. Tissue distribution of terbinafine in rats. J. Pharm. Sci. 2001, 90, 1817-1828. [CrossRef] [PubMed]

31. Seidel, D.; Meissner, A.; Lackner, M.; Piepenbrock, E.; Salmanton-Garcia, J.; Stecher, M.; Mellinghoff, S.; Hamprecht, A.; Duran Graeff, L.; Kohler, P.; et al. Prognostic factors in 264 adults with invasive Scedosporium spp. and Lomentospora prolificans infection reported in the literature and FungiScope((R)). Crit. Rev. Microbiol. 2019, 45, 1-21. [CrossRef] [PubMed]

32. Lamoth, F.; Kontoyiannis, D.P. Therapeutic Challenges of Non-Aspergillus Invasive Mold Infections in Immunosuppressed Patients. Antimicrob. Agents Chemother. 2019, 63, e01244-19. [CrossRef]

33. Rivero-Menendez, O.; Cuenca-Estrella, M.; Alastruey-Izquierdo, A. In vitro activity of olorofim (F901318) against clinical isolates of cryptic species of Aspergillus by EUCAST and CLSI methodologies. J. Antimicrob. Chemother. 2019, 74, 1586-1590. [CrossRef] [PubMed]

34. Rivero-Menendez, O.; Cuenca-Estrella, M.; Alastruey-Izquierdo, A. In vitro activity of APX001A against rare moulds using EUCAST and CLSI methodologies. J. Antimicrob. Chemother. 2019, 74, 1295-1299. [CrossRef] [PubMed]

(C) 2020 by the authors. Licensee MDPI, Basel, Switzerland. This article is an open access article distributed under the terms and conditions of the Creative Commons Attribution (CC BY) license (http://creativecommons.org/licenses/by/4.0/). 